\title{
Fostering Societal Impact and Job Satisfaction: The Role of Performance Management and Leader-Member Exchange.
}

\author{
Robin BAUWENS, Msc., MA. ${ }^{12}$ \\ Mieke AUDENAERT, PhD. ${ }^{2}$ \\ Adelien DECRAMER, PhD. ${ }^{2}$ \\ Faculty of Economics and Business Administration, Ghent University, \\ Tweekerkenstraat 2, B-9000 Ghent, Belgium.
}

\begin{abstract}
Acknowledgement
We thank the participants of the 2017 conferences of the European Group of Public Administration Annual (EGPA) and the Dutch HRM network, as well as two anonymous reviewers for feedback on earlier drafts of this paper. Also, the feedback of Bert George and Bram Verschuere was helpful in improving the manuscript.
\end{abstract}

Accepted for publication in PUBLIC MANAGEMENT REVIEW 


\title{
Fostering Societal Impact and Job Satisfaction: The Role of Performance Management and Leader-Member Exchange.
}

\begin{abstract}
Performance management (PM) can alienate employees from experiencing societal impact. This is problematic since societal impact influences employees' job satisfaction. To avoid such unintended effects, we investigate two conditions under which PM could instead benefit the societal impact and job satisfaction of employees: consistency and leader-member exchange. Results show consistent PM fosters job satisfaction, mediated by societal impact and moderated by leader-member exchange. Public organisations should streamline expectations communicated through PM and constructive leader relationships could reinforce this process. By examining the conditions under which PM can avoid unintended effects on employees, we add to the debate on PM effectiveness.
\end{abstract}

Keywords: performance management; societal impact; job satisfaction; leader-member exchange; higher education 


\section{Introduction}

Fast-tracked by New Public Management (NPM), public organisations have adopted performance management $(\mathrm{PM})$ to measure and progress employees' performances through systematic goalsetting, combined with regular feedback and evaluation of their employees' efforts (Brown 2004; Van Dooren, Bouckaert, and Halligan 2015). While PM targets efficient and effective organisations, it can also result in unintended effects on employees (Diefenbach 2009; Melo, Sarrico, and Radnor 2010). In particular, PM's focus on efficiency and effectiveness has been suspected of alienating public employees from the societal meaning and relevance of their job (Oh and Lewis 2009; Tummers, Bekkers, and Steijn 2009; 2012). This is problematic, as societal impact, defined as the extent to which employees sense opportunities to benefit society and societal problems in their job, constitutes a central part of public employees' wellbeing (Steijn and Van der Voet forthcoming; Tummers, Bekkers, and Steijn 2009; Van Loon, Vandenabeele, and Leisink 2015). Especially in public service environments, societal impact is considered tied to other important aspects of public employees' wellbeing, like their job satisfaction (Grant 2007; Taylor and Westover 2011). Hence, not experiencing societal impact could have its consequences: job characteristics theory (Morgeson and Humphrey 2006) suggests that when public employees perceive low societal impact in their job, their job satisfaction could suffer in response (Pick and Teo 2017).

Despite such observations, traditional public administration scholarship in this area has focused on whether PM increases efficiency and productivity (Diefenbach 2009; Favero, Meier, and O'Toole 2016). While PM could entail advantages for efficiency and productivity measures, less attention has focused on how PM affects public employees, which could result in unintended effects on employees' attitudes and wellbeing (Kerpershoek, Groenleer, and de Bruijn 2016; Noblet 
and Rodwell 2009). Knowledge on how to prevent PM from having such unintended wellbeing effects is necessary, as public organisations require a healthy workforce to deliver public service in efficient and effective ways (Kalgin et al. 2018).

Past research proposes that PM's unintended wellbeing effects could be tempered when attention is devoted to (1) how PM is implemented (Franco-Santos and Doherty 2017; Selden and Sowa 2011) and (2) how leaders that are in charge of PM's implementation behave (Butterfield, Edwards, and Woodall 2004; Campbell, Lee, and Im 2016). In public organisations, this combination of PM implementation and leader behaviour is referred to as people management (Knies and Leisink 2018). People management is important to employees' wellbeing for at least two reasons. A first reason is that employees' wellbeing is tied to how they perceive PM is implemented in their organisation or organisational unit (Bauwens et al. forthcoming; Jacobsen and Andersen 2014). Especially in public organisations, scholars suggest that attention should be paid to the consistency with which PM is communicated and applied to avoid that PM embargoes employees' wellbeing (Audenaert et al. forthcoming; Van Thielen et al. 2018; Van Waeyenberg et al. 2017). Recurrently public employees need to comply with quantitative performance targets (e.g., number of clients serviced; time devoted to each client). However, public employees also provide societal services that are more difficult to quantify or not followed up and evaluated to the same extent (Pollitt 2013; Van der Wal, De Graaf, and Lawton 2011). Such complex demands typically create inconsistent goals and expectations that cause frustration or confusion and compromise employees' wellbeing (Jung 2014). When PM signals very different, or even inconsistent goals and expectations to employees, this could undermine employees' perceptions of their societal impact (Tummers, Bekkers, and Steijn 2009) and ultimately their job satisfaction (Fletcher and Williams 1996; Jung 2011). Therefore, signalling theory (Spence 1973) suggests that when organisations communicate and maintain the same goals and expectations throughout goal- 
setting, feedback and evaluation of their employees' efforts (i.e. PM consistency), these employees feel are better informed and feel more respected and in control. This lowers the demanding effects of having to deal with inconsistent goals and expectations (Biron, Farndale, and Paauwe 2011).

A second reason is that public organisations have decentralised several key administrative and human resource management-tasks to leaders in the lower segments of the organisation. This implies that those leaders can alter how the implementation of PM affects employees (Butterfield, Edwards, and Woodall 2004; Moynihan and Wright 2012). Hence leader behaviour "may be an important factor in determining whether public organisations can reap the benefits of PM" (Campbell, Lee, and Im 2016, 795). Recent studies underscore leader-member exchange (LMX) as a way to look at public leader behaviour (e.g., Tummers and Knies 2013; Vigoda-Gadot and Beeri 2015). LMX posits that leaders have qualitatively different relationships with each of their individual employees, characterised by discrepancies in the social exchange of resources (Graen and Uhl-Bien 1995; Yeo et al. 2015). The eminence of LMX emerges from observations that these differential relationships typically function as a 'lenses' through which employees interpret PM and other management arrangements in their professional context (Audenaert et al. forthcoming; Bos-Nehles and Audenaert 2019). Despite scholars asserting that LMX could be a catalyst for how PM affects employees (den Hartog, Paauwe, and Boselie 2004; Varma, Budhwar, and Denisi 2008), few studies have examined PM and LMX in conjunction, let alone in relation to employees' wellbeing.

The arguments above illustrate that how PM is implemented and how leaders behave could be important contingencies for how PM affects employees' wellbeing. Nevertheless, current public management literature has seldom empirically combined both aspects of people management to arrive at such a coherent understanding of how PM affects employees (Audenaert et al. 
forthcoming; Campbell, Lee, and Im 2016; Cho and Poister 2013). Therefore, the present article focuses on the following research questions:

1. What is the association between PM consistency and employees' wellbeing (i.e. job satisfaction and perceived societal impact)?

2. What role does perceived societal impact play, as a potential mediator between PM consistency and employees' job satisfaction?

3. How does leader behaviour (i.e. LMX) affect the aforementioned associations?

In answering these questions, our study progresses our understanding of how PM can avoid unintended effects on employees in the public sector and, hence, offers insights on PM effectiveness in two ways. First, by examining how PM is implemented (i.e. PM consistency) in tandem with how leaders behave during this process (i.e. LMX), as suggested by people management literature (Butterfield, Edwards, and Woodall 2004; Knies and Leisink 2018), the study taps into the literature stream arguing that a more holistic understanding of how PM affects employees is necessary (Diefenbach 2009). Second, the study considers societal impact as an outcome of PM and therefore responds to Moynihan, Pandey, and Wright's (2012) call to include societal impact in PM research as it is (theoretically) deemed important to consider both PM and societal impact as key motivators for employees (Anderson and Stritch 2015). Moreover, we complement empirical knowledge by focusing on public universities, where wellbeing concerns over PM are imminent (Bauwens et al. forthcoming; Franco-Santos and Doherty 2017; Levecque et al. 2017) and societal impact is gaining increasing attention (Watermeyer 2015; 2016). 


\section{Theoretical Framework}

Figure 1 shows the model tested in this study. We propose that PM consistency and LMX jointly affect employees' job satisfaction, mediated by perceptions of societal impact in their job. This model assumes that LMX is a moderator of the first and second stages of the mediated effect of PM consistency on job satisfaction. Following Edwards and Lambert (2007, 4), the combination of these effects implies a moderated mediation, more specific a direct effect and first stage moderation model, in which the first two paths of a mediating variable are moderated by another.

\section{[FIGURE 1 NEAR HERE]}

In explaining this model, we draw on signalling theory (Spence 1973) and job characteristics theory (Morgeson and Humphrey 2006), belonging to the broader theoretical perspectives of social information processing and job design respectively. Information processing theories, like signalling theory, are often used to explain the effects of PM (e.g., Biron, Farndale, and Paauwe 2011; Bowen and Ostroff 2004), while job design theories have typically been adopted in studies on societal impact and job satisfaction (Oldham and Hackman 2010; Van der Voet and Steijn forthcoming). Since both theoretical perspectives focus on employees' connections to other people (i.e., relational mechanisms; Grant 2008), previous research shows that both theoretical perspectives can be combined to explain the predictors and outcomes of employees' perceived societal impact (Grant 2008). In line with such a 'relational approach' (Broadbent 2010), we also focus on LMX, a relational approach to examine leader behaviours (Caillier 2017; Fernandez 2008). 
In the following sections, we will first discuss the associations between PM consistency and societal impact and job satisfaction respectively. Subsequently, we expand on the mediating role of perceived social impact and the moderating role of LMX.

\section{Signalling Effects of PM Consistency on Employees' wellbeing}

In understanding employees' affective responses to PM, scholars underscore the importance of employees' perceptions (Jacobsen and Andersen 2014). The underlying logic is explained by signalling theory (Spence 1973). Signalling theory considers PM not only as a series of metrics, but also as a communication instrument that enables organisations to communicate to their employees how they should act and behave. Communication is central to PM and provides employees with signals of the organisational mission and values (Biron, Farndale, and Paauwe 2011). Such signals can be implicit, incomplete or inconsistent. Nevertheless, employees are not passive recipients of these PM signals, but actively interpret them to make inferences about expected attitudes and behaviours in the workplace, ultimately affecting their feelings and actions (Bowen and Ostroff 2004; Jacobsen and Andersen 2014).

If public organisations wish to transmit their mission and values to employees in a clear and effective manner, it is important that PM sends out signals that are consistent (Li, Sanders, and Frenkel 2012; Piening, Baluch, and Ridder 2014). We recall that PM measures and progresses employees' performances through setting goals, providing feedback and evaluating employees on their efforts (Selden and Sowa 2011). PM consistency implies that communication across goalsetting, feedback and evaluation is coherent. In other words, that regardless of the time or situation, PM sends similar messages, free from contradictions or mixed signals (Bowen and Ostroff 2004). This is especially important in public organisations, where employees typically face multiple and 
complex job demands (Jung 2011; Van der Wal, De Graaf, and Lawton 2011). Inconsistent rules and unpredictable expectations can create strain and confusion that impact employees' wellbeing (Bowen and Ostroff 2004; Townsend et al. 2012). For example, if PM fails to follow-up or evaluate employees on criteria which were communicated beforehand (e.g., stressing the societalness of goals, tasks and expectations in goals-setting, but not taking this into account during feedback and evaluations), such inconsistency could result in withdrawal, resentment and ultimately lower employee wellbeing (Van Waeyenberg et al. 2017).

By contrast, consistent PM manages to reduce such incongruent signals and refocuses employees' attention, with benefits for their wellbeing (Piening, Baluch, and Ridder 2014). If PM is consistent (e.g., coherent communication about how and when employees' work can benefit both organisational and societal purposes during goal-setting, feedback and evaluation), employees can more easily make sense of the management-intentions behind the signalled goals, tasks and expectations (e.g., public organisations wishing to fulfil a more prominent role in society). This allows employees to see how their own goals, tasks and expectations fits within the broader organisational mission and values (Li, Sanders, and Frenkel 2012; Piening, Baluch, and Ridder 2014; Van Thielen et al. 2018), enabling those employees to better assess the societal meaningfulness of their jobs (Anderson and Stritch 2015; Bellé 2013; Kim and Wright 2004).

Nevertheless, a consistent PM system is not necessarily supportive for employees. However, recent research by Matta et al. (2017) revealed that being consistent, even in an unsupportive manner, is still more advantageous for employees' wellbeing than being inconsistent. Indeed, when employees consistently receive clear information, organisational goals and expectations become more predictable to them (i.e. they know what to expect). Such predictably is associated with higher employee wellbeing (Van Waeyenberg et al. 2017). In what follows, we 
discuss how PM consistency affects two particular aspects of wellbeing: perceived societal impact and job satisfaction.

\section{PM Consistency and Perceived Societal Impact}

Perceived societal impact refers to the extent to which employees' view possibilities to contribute to societal problems and welfare in their job (Van Loon, Vandenabeele, and Leisink 2015). The concept bears similarities to Grant's (2007) prosocial impact, but also includes the impact of one's job on society in addition to meaningful impact on others (Leisink and Steijn 2009; Van Loon et al. 2018). Being a type of subjective PSM-fit, perceived societal impact constitutes a useful measure of employees' wellbeing in public organisations and public service environments (Caillier 2016; Steijn and Van der Voet forthcoming). Despite scholars arguing that public organisations have a responsibility in making their employees feel they are contributing to society (Leisink and Steijn 2009; Perry and Hondeghem 2008), existent research has mostly focused on employees’ motivation for public service (i.e. public service motivation; PSM). Whether public employees feel their job actually offers opportunities with societal meaningfulness (i.e. perceived societal impact) remains underresearched (Moynihan, Pandey, and Wright 2012; Stritch and Christensen 2014).

To assess the societal impact of their job, employees seek tangible information from their work environment (Grant 2008). As a key organisational influence, PM can provide employees with such information (Moynihan and Pandey 2010; Pollit 2013). PM aims to stimulate employees towards improved performances and ensures their goals, tasks and expectations are in line with the mission and values of the broader organisation (Van Dooren, Bouckaert, and Halligan 2015; Selden and Sowa 2011). Since public organisations are considered organisations with unique societal missions and values (Knies and Leisink 2018), PM helps employees to understand how their goals, 
tasks and expectations contribute to the societal mission and values (Van Dooren, Bouckaert, and Halligan 2015; Wright, Moynihan, and Pandey 2012).

Following signalling theory (Spence 1973), PM is more successful at fostering such understanding among employees, when the messages it sends to them across goal-setting, feedback and evaluation are consistent with one another (Biron, Farndale, and Paauwe 2011; Bowen and Ostroff 2004). Consistent communication about the organisational mission, values and goals, as well as how employees' goals, tasks and expectations contribute to them, sends coherent signals to employees about the organisational and societal significance of their own goals, tasks and expectations. This can result in employees finding their job more meaningful (Anderson and Stritch 2015; Bellé 2013; Kim and Wright 2004) and influences those employees in socially constructing their professional identity as public servants (Alvesson and Kärreman 2007; Ehrnrooth and Björkman 2012).

By contrast, if PM is inconsistent and sends different messages across goal-setting, feedback and evaluation, employees' goals, tasks and expectations become ambiguous and unclear (Van Waeyenberg et al. 2017). In such situations of goal ambiguity and value conflict, it is much more difficult for employees to develop a coherent understanding about the organisational and societal significance of their goals, tasks and expectations (Tummers and Knies 2013). Furthermore, such inconsistency is likely to create confusion and scepticism among regarding their societal impact employees (i.e. 'we can't change anything, they don't really intend to help society in this or that way'), causing such PM arrangements to alienate employees from 'the real world' (Tummers, Bekkers, and Steijn 2009; 2012).

Therefore, consistent PM manages to increase employees' perceived societal impact, because it consistently connects the general mission, values and goals of public organisations (which in public organisations are often societally orientated) with the concrete goals and 
expectations of employees (Wright, Moynihan, and Pandey 2012), allowing them to see more organisational and societal value in their job (Anderson and Stritch 2015; Tummers and Knies 2013).

Hypothesis 1(a). PM consistency positively affects employees' perceived societal impact.

\section{PM Consistency and Job Satisfaction}

Job satisfaction is a feeling that results from employees' interaction with their work environment and is considered to show stronger relations with work and job characteristics than with individual characteristics (Wright and Davis 2003). Employees' perceptions of PM have been linked to job satisfaction before, but thus far such studies have remained inconclusive (e.g., Fletcher and Williams 1996; Selden and Sowa 2011; Yang and Kassekert 2009). Other scholars point out the conditional nature of this association (Decramer et al. 2015; Franco-Santos and Doherty 2017). In line with this 'conditional view', we argue that employees are more satisfied in their job when public organisations use PM to clarify to employees how their job fits the broader organisational mission, values and goals (Decramer et al. 2015; Kalgin et al. 2018; Perry and Hondeghem 2008). Following signalling theory (1973), to achieve such understanding, clear and consistent information is vital (den Hartog et al. 2013; Cho and Poister 2013; Piening, Baluch, and Ridder 2014). By contrast, when PM is ambivalent and subjected to swift changes, employees become more calculative in their job and are likely to be less satisfied (Teelken 2015). Similar observations between PM consistency and job satisfaction were made in other public and private organisational settings, such as hotels, restaurants and public hospitals (e.g., den Hartog et al. 2013; Li, Sanders, and Frenkel 2012; Piening, Baluch, and Ridder 2014). Employees are more satisfied in their job 
when they receive consistent information from PM, as this creates clarity and predictability of where they need to direct their focus and reduces potential strains of having to deal with incongruent goals, tasks and expectations (Fletcher and Williams 1996; Jung 2014; Sella and Sowden 2011).

Hypothesis 1(b). PM consistency positively affects employees' job satisfaction.

\section{Perceived Societal Impact as Mediator}

Distinguishing a degree of societal impact in one's job is argued to have broader wellbeing benefits (Van Loon, Vandenabeele, and Leisink 2015). Hence, we propose that employees' perceived societal impact and job satisfaction are related. We base our argument on job characteristics theory, which was developed by Hackman and Oldham (1976) but enjoys more current attention in its retheorised form by Morgeson and Humphrey (2006). This re-theorised form devotes more attention to the social and societal aspects of work (Oldham and Hackman 2010). Job characteristics theory states that employees' perceptions of their job characteristics (e.g., significance of expected tasks, contact with societal beneficiaries) result in psychological states (e.g., experienced impact and/or meaningfulness) that influence work-related outcomes among those employees (e.g., job satisfaction, job performance). The theory leads to suggest that when employees perceive their tasks as significant (e.g., to society of societal beneficiaries), they will derive a sense of societal impact from their work, that is likely to boost their job satisfaction (Oldham and Hackman 2010; Stritch and Christensen 2014; Wright and Davis 2003). By contrast, if employees do not feel that their job offers sufficient opportunities to contribute to society, frustration and dissatisfaction may ensue (Grant 2007; Taylor and Westover 2011; Van Loon, Vandenabeele, and Leisink 2015). We 
argue that this is especially true for public employees, for which societal impact is an important pillar of their professional identity (Leisink and Steijn 2009; Perry and Hondeghem 2008). This is further endorsed in other studies, suggesting a significant relationship between the perceived societal impact of employees' job and their job satisfaction (Breaugh, Ritz, and Alfes 2018; Steijn and Van der Voet forthcoming; Van Loon, Vandenabeele, and Leisink 2015).

Since (1) consistent PM allows employees to better understand the organisational and societal meaningfulness of their job (Anderson and Stritch 2015; Bellé 2013; Kim and Wright 2004), as stated in Hypothesis 1(a) and (2) perceptions of societal impact are beneficial for employees' job satisfaction (Steijn and Van der Voet forthcoming), we argue that perceived societal impact mediates between employees' perceptions of PM consistency and their job satisfaction. We expect this relationship to be partial, as we also hypothesise a direct relation of PM consistency on job satisfaction, as proposed in Hypothesis 1(b).

Hypothesis 2. Perceived societal impact partially mediates the relationship between PM consistency and employees' job satisfaction.

\section{LMX as Moderator}

LMX has emerged as an influential approach to study leader behaviour in public organisations (Crosby and Bryson 2018; Tummers and Knies 2013; Van Wart 2014). LMX posits that leaders have qualitatively different relationships with each of their individual employees (Graen and UhlBien 1995; Yeo et al. 2015), characterised by discrepancies in the social exchange of resources. These exchanged resources can be very broad, ranging from information and feedback to unique participation opportunities in impactful projects (Tummers and Knies 2013). High-quality LMX relationships are characterised by a strong exchange of such resources, resulting in effective 
working relationships that are high in trust, respect and job-related communication. In low-quality LMX relationships, such exchanges are reduced to economic exchanges of work for payment (Harris, Wheeler, and Kacmar 2009; Yeo et al. 2015).

While direct effects of LMX on employees' wellbeing are well-established (Fernandez 2008; Yeo et al. 2015), scholars suggest that LMX can also moderate how PM affects employees (den Hartog, Paauwe, and Boselie 2004; Varma, Budhwar, and Denisi 2008). Such moderating effects originate from the idea that LMX is about more than exchanging resources, but that the quality of the relationships that employees maintain vis-à-vis their leaders functions as 'lens' through which employees evaluate PM and other management practices (Bos-Nehles and Audenaert 2019). Nevertheless these assertions, few scholars have put them to empirical scrutiny (Audenaert et al. forthcoming; Rosen, Harris, and Kacmar 2011). We argue that LMX reinforces the effects of PM consistency in our model in two ways.

First, a constructive leader-employee relationship could fulfil a clarifying role in PM, by strengthening existing messages (Audenaert et al. forthcoming; Cho and Poister 2013; Rosen, Harris, and Kacmar 2011) or providing employees with additional information when communication on the organisational mission and values is inconsistent or lacking (Wright, Moynihan, and Pandey 2012; Tummers and Knies 2013). In constructive leader-employee relationships, employees are more likely to receive more valuable resources (e.g., challenging opportunities, unique information) that aid them in assessing the societal meaningfulness and impact of their job (Caillier 2017; Grant 2012). For example, in a high-quality LMX relationship, a leader can bring employees in contact with his/her professional network or people that could benefit from employees' work (Tummers and Knies 2013). In these ways, leaders can highlight or add societal impact to employees' goals and expectations. As this further elucidates to employees how the societal mission and values of the organisation are linked to their goals and expectations 
(Perry and Hondeghem 2008; Wright, Moynihan, and Pandey 2012), this could improve the consistency of PM. Therefore, we argue that having a high-quality LMX relationship strengthens the effect of PM consistency on employees' perceived societal impact.

Hypothesis 3(a). LMX positively moderates between PM consistency and societal impact.

Second, in constructive leader-employee relationships, leaders not only fulfil a clarifying role in PM (Audenaert et al. forthcoming), but are also more attentive to employees' needs to comply with the organisational mission, values and goals, and their specific goals, tasks and expectations (den Hartog et al. 2013). Under these conditions, employees could experience PM as more supporting and feel much more valued and respected (Audenaert, Vanderstraeten, and Buyens 2017; Caillier 2017), which might result in higher job satisfaction levels (Fletcher and Williams 1996; Yang and Kassekert 2009).

Hypothesis 3(b). LMX positively moderates between PM consistency and job satisfaction.

In the previous sections, we used job characteristics theory (Morgeson and Humphrey 2006) to propose that consistent PM increases employees' societal impact perceptions, leading to improved job satisfaction (Hypothesis 2). If, based on signalling theory (Spence 1973), we assume that the association between PM consistency and perceived societal impact is also stronger for employees in a high-quality LMX relationship (Hypothesis 3(a)), we argue that the mediation of perceived societal impact is positively moderated by LMX, leading to a moderated mediation (Edwards and Lambert 2007), as shown in Figure 1. 
Hypothesis 3(c). LMX positively moderates the mediation of perceived societal impact between PM consistency and employees' job satisfaction.

\section{Method}

\section{Empirical Context}

Our study is set in public higher education, a particular relevant setting for the study of PM, societal impact and job satisfaction. Public universities can be considered public organisations with a societal and organisational mission that centres on knowledge management (i.e. research and teaching or knowledge creation and knowledge dissemination; Rowley 2000). Following NPMinspired reforms in the European higher education sector targeted at efficiency, effectiveness and accountability, public universities have adopted PM (Brouker, De Wit, and Leisyte 2016; Melo, Sarrico, and Radnor 2010) and decentralised its responsibilities to leaders in different institutional segments (McCormack, Propper, and Smith 2014). Universities have always stimulated their academic employees' societal impact (Van der Weijden, Verbree, and Van Den Besselaar 2012), making it an important aspect of their identity (Winter 2009). However, new is the way in which societal impact is inscribed into a PM-agenda, where the attention is shifting to also use research in activities with broader societal impact (Watermeyer 2015), which offer employees with opportunities to interact with parties that can benefit from their work, ultimately influencing their ideas about the societal impact of their job (Taylor and Westover 2011). While societal impact increases in importance (Van der Weijden, Verbree, and Van Den Besselaar 2012), higher educations' PM remains very much centred around scholarly publications (Decramer et al. 2012; Melo, Sarrico, and Radnor 2010), at the cost of research serving a broader societal relevance (Watermeyer 2015). This illustrates that academic employees are regularly confronted with 
inconsistent goals and expectations (Dietz and Scheel 2017). Such observations coincide with mounting concerns over the potential harming effects of PM on academic employees' wellbeing (Fredman and Doughney 2012; Franco-Santos and Doherty 2017), raising calls to further examine leadership and management in this sector (Broadbent 2010; McCorkmack, Propper, and Smith 2014). While academic employees' wellbeing enjoys generous scholarly attention (Levecque et al. 2017), few have made the empirical connection with PM (Bauwens et al. forthcoming; FrancoSantos and Doherty 2017).

In this study, we focus on higher education in Flanders, which is well-embedded in the (continental) European higher education area (Brouker, De Wit, and Leisyte 2016). Following the legal obligation for regular follow-up and evaluation of academic employees, PM is implemented in each of those institutions (Decramer et al. 2012). In 2014, the institution under study kick-started a strategic plan to create an environment where the societal impact of research is stimulated and encouraged. The plan considers the societal impact of research as something that iteratively emerges during the lifecycle of a research project and should be considered during a broad approach to goal-setting, follow-up and evaluation, that is PM. Two distinguishable characteristics of the Flemish landscape are (1) the predominance of public institutions, which depend on the regional government for funding and regulation (Brouker, De Wit, and Leisyte 2016) and (2) the fact that junior academic employees, such as $\mathrm{PhD}$ students, are considered full-employees with an employment contract (Levecque et al. 2017). Within the institution under study, we focus on academic research employees, under the auspices of their respective research leaders. These research leaders are responsible for PM's execution within their respective research teams (Decramer et al. 2012). 


\section{Data Collection}

To minimise contextual effects of institutions (Melo, Sarrico, and Radnor 2010) and scientific disciplines, this study focuses on PM within the STEM faculties (science, technology, engineering and mathematics) of a major public university in Flanders, Belgium (41,000 students / 9000 academic employees). We choose STEM academic employees since the idea of societal impact enjoys a longer history in these research fields (Davies 2013). For comparability of job characteristics, we limited the analyses to junior academic employees, i.e. pre-docs and post-docs (Dietz and Scheel 2017). Compared to other highly-educated peers, junior academic employees' risk of facing unintended wellbeing effects is twice is as high. Management arrangements such as PM have been designated as the culprit (Levecque et al. 2017). In September 2016, an electronic survey (Qualtrics) was sent to 4,586 junior academic employees. We received 532 valid responses. This response is in line with other studies on public higher education (Bauwens et al. forthcoming; Decramer et al. 2012). On average, participants were female (56.50\%), 30.95 years old $(\mathrm{SD}=6.23)$ and employed as PhD bursaries $(66.00 \%)$. They mostly conducted research in the fields of theoretical sciences $(21.60 \%)$ and engineering $(21.60 \%)$, while the majority looked back on a tenure of 4.81 years $(\mathrm{SD}=3.18)$. Selective non-response analyses revealed slightly more female researchers $\left(\chi^{2}(1)=19.903, \mathrm{p}<.001\right)$, postdocs $\left(\chi^{2}(1)=21.46, \mathrm{p}<.001\right)$ and researchers in medicine-related fields $\left(\chi^{2}(1)=6.443, \mathrm{p}<.010\right)$ in our sample compared to the institutional population. This was at the expense of male researchers, $\mathrm{PhD}$ grant recipients and engineering researchers respectively. These observations reveal the need to control for these variables in our model (Berneth and Aguinis 2016). 


\section{Measures}

Variables were measured on seven-point Likert scales $(1=$ strongly disagree $; 7=$ strongly agree $)$. Supporting construct validity, Cronbach alphas $(\alpha)$ ranged from .87 to .94 . Full items and factor loadings are in Appendix 1.

PM consistency was measured using Bednall et al.'s (2014) six-item scale. A sample item is 'The planning, monitoring and evaluation [of my research] is designed in such a way that desired behaviours are being encouraged'. $(\alpha=.94)$.

Perceived societal impact was measured using the four items from Van Loon et al. (2015), based on earlier work by Leisink and Steijn (2009). A sample item is 'Someone with a job like mine contributes to solving societal problems'. $(\alpha=.91)$.

Job satisfaction was assessed by the three items from the Michigan organisational assessment questionnaire by Cammann et al. (1983). One item was reversed due to negative wording. A sample item is 'All in all, I am satisfied with my job'. $(\alpha=.87)$. This scale is regularly used to measure job satisfaction in public organisations and has previously demonstrated good reliabilities (e.g., Breaugh, Ritz, and Alfes 2018; DeHart-Davis and Pandey 2005).

Leader-member exchange was measured using the eight items from Bauer and Green (1996). An example item is 'My research leader recognises my potential'. $(\alpha=.94)$.

Control variables were added for gender $(0=$ Male, $1=$ Female $)$, which has previously correlated significantly with societal impact and job satisfaction (Van Loon et al. 2015). Following Berneth and Aguinis (2016), we also controlled for function and tenure in studying management outcomes. Finally, we considered the scientific field, which has shown to be related to societal job impact (Davies 2013). 


\section{Common Source Bias}

Our study depends on self-reported data from a single survey, making common source bias (CSB) a liability (Favero and Bullock 2014). Despite its shortcomings, self-reported data use is warranted when (1) studying individual perceptions and beliefs - which is the core of this study, (2) other data sources are not readily available, (3) potential CSB can be detected through a one-factor test and (4) variables have not previously been identified as CSB-sensitive (George and Pandey 2017). To avoid CSB in the data collection, we followed earlier recommendations (Lee, Benoit-Bryan, and Johnson 2012; Podsakoff, MacKenzie, and Podsakoff 2012) by (i) only including priorvalidated measures, (ii) stressing respondents' anonymity, (iii) their personal opinions and voluntary participation and (iv) inducing a psychological lag time by separating independent and dependent variables in different chapters. After the data collection, we conducted a one-factor test (all items on one factor) and a common-latent factor test (all items on their factor, as well as on a common factor). Both models fitted the data significantly worse (see Results), suggesting considerable CSB is absent. Finally, we tested moderating effects, which further reduce the chances of significant CSB (George and Pandey 2017).

\section{Data Analysis}

We tested moderated mediation following Edwards and Lambert's (2007) method. First, we examined mediating and moderating in isolation. Second, we combined those effects in a moderated mediation model. Data were analysed using structural equation modelling (SEM), as previous work (Aguinis, Edwards, and Bradley 2017; Edwards and Lambert 2007) underscores the this technique's advantages to test complex mediations and take into account measurement error. SEM typically unfolds over two steps (Kline 2015). First, the factor structure of the latent variables in the proposed model is examined through confirmatory factor analysis (CFA), resulting in 
different measurement models. Second, the different causal paths between the latent variables in the model are examined with SEM, resulting in different structural models. In both steps, we evaluated the model fit of nested models through frequently-reported fit indices (Kline 2015) such as the comparative fit index (CFI), Tucker-Lewis index (TLI), root mean square error of approximation (RMSA) and standardised root mean square residual (SRMR). We also reported the chi-square value with Satorra-Bentler correction, which gives more stringent estimates of model fit and corrects for potential non-normality (Kline 2015). To check the robustness of the mediation and moderated mediation, we calculated bootstrapped confidence intervals for the indirect effects (Preacher and Hayes 2008). We also computed the index of moderated mediation (Hayes 2015), in which a confidence interval without zero indicates moderated mediation. Analyses were performed in R 3.2.5 with lavaan (Rosseel 2012).

\section{Results}

Table 1 shows the descriptive statistics and correlations. Correlations remained within the limits of |.800|. Values for the variance inflation factors (VIF) remained below 10.00, ranging between 1.13 and 2.06, showing no indications of multicollinearity (Kline 2015).

\section{[TABLE 1 NEAR HERE]}

\section{Factor Structure Tests}

Table 2 displays the measurement models' fit indices. Confirming our hypothesised factor structure, a four-factor model (PM consistency, LMX, perceived societal impact, job satisfaction) fits the data well with CFI and TLI very close to .950, RMSEA near .060 and SRMR approaching .080 (Kline 2015). All items loaded sufficiently on their factors $(\lambda>.500 \mid)$ with standardised factor 
loadings ranging between .717 and .930 and the average variance extracted (AVE) ranging between .618 and .777. A single-factor model $\left(\Delta \chi^{2} \mathrm{s-B}=1712.177 ; \Delta \mathrm{df}=6 ; p<.001\right)$ or common factor model $\left(\Delta \chi^{2} \mathrm{~S}-\mathrm{B}=255.800 ; \Delta \mathrm{df}=2 ; p<.001\right)$ fitted the data significantly worse. Furthermore, a three-factor models in which PM consistency and LMX shared a factor $\left(\Delta \chi^{2} \mathrm{~s}-\mathrm{B}=770.701 ; \Delta \mathrm{df}=\right.$ $3 ; p<.001)$ or perceived societal impact and job satisfaction shared a factor $\left(\Delta \chi^{2} \mathrm{~s}-\mathrm{B}=612.487 ; \Delta \mathrm{df}\right.$ $=3 ; p<.001)$, also showed significant lower fit.

\section{[TABLE 2 NEAR HERE]}

\section{Mediation and Moderation tests}

Table 3 displays the structural models' fit indices. We tested the mediation of perceived societal impact between PM consistency and job satisfaction, not taking into account LMX (Edwards and Lambert 2007). In line with the hypotheses, we expect partial mediation, in which PM consistency has a direct path on job satisfaction and an indirect path through perceived societal impact. This model showed suboptimal fit to the collected data, with all fit indices approaching satisfying values except for the high SRMR. We compared this model with a full mediation model (PM consistency only having an indirect effect on job satisfaction) and a model with direct effects (no mediation). The results demonstrate a partial mediation model to fit the data significantly better than a full $\left(\Delta \chi^{2} \mathrm{~s}-\mathrm{B}=6.810 ; \Delta \mathrm{df}=1 ; p<.05\right)$ or a no-mediation model $\left(\Delta \chi^{2} \mathrm{~s}-\mathrm{B}=17.958 ; \Delta \mathrm{df}=2 ; p<.001\right)$. For robustness, we assessed indirect and total effects with a 95\% confidence interval (BootCI) through a bootstrapping procedure with 5,000. PM consistency's unstandardized indirect effect on job satisfaction was $.076($ BootCI $=0.073-0.078, p<.010)$, total effect was $.773($ BootCI $=.692-.910$, 
$p$ <.001). Both the indirect and total effect were significant in the bootstrapped samples, preliminary supporting Hypothesis 1(a,b) and Hypothesis 2.

\section{[TABLE 3 HERE]}

Third, we tested whether LMX moderated between PM consistency and perceived societal impact (first-stage moderation), as well as job satisfaction (direct-effect moderation). Additionally, we examined the coexistence the moderation effects (combined moderation). A combined moderation model approaches optimal fit, while a first-stage $\left(\Delta \chi^{2} \mathrm{~s}-\mathrm{B}=34.253 ; \Delta \mathrm{df}=1 ; p<.05\right)$ or direct-effect moderation model $\left(\Delta \chi^{2}\right.$ s-B $\left.=3.026 ; \Delta \mathrm{df}=3 ; p<.001\right)$ fitted significantly worse. LMX has significant moderating effects in both the first-stage moderation model $(B=.145, p<.010)$ and direct-effect model $(B=-.071, p<.050)$, but in combined moderation, the significant moderation for LMX on the PM consistency-job satisfaction path disappears $(B=-.053, p>.100)$. These observations fully underscore Hypothesis 3(a) and disconfirm Hypothesis 3(b).

\section{Moderated Mediation Tests}

Finally, we examined the simultaneous occurrence of mediations and moderations in a moderated mediation. Our approach was similar to the moderation tests, comparing partial mediation models that include moderation effects of LMX on the links of PM consistency with perceived societal impact (first-stage moderated mediation) and job satisfaction (direct-effect moderated mediation), as well as their co-existence (combined moderated mediation). Again, the model was close to optimal fit, save for the SMSR. By contrast, the first-stage model performed significantly worse $\left(\Delta \chi^{2} \mathrm{~s}-\mathrm{B}=34.186 ; \Delta \mathrm{df}=2 ; p<.001\right)$, while the direct-effect model demonstrated no significant improvement $\left(\Delta \chi^{2} \mathrm{~S}-\mathrm{B}=0.001 ; \Delta \mathrm{df}=2 ; p<.100\right)$. Counter to the moderation tests in the previous paragraph, LMX' moderation effect is significant in all the moderated mediation models, including 
the final combined model: LMX positively moderates the path between PM consistency and perceived societal impact and negatively moderated the path between PM consistency and job satisfaction.

The final model is depicted in Figure 2. Tenure had a negative link with PM consistency ( $B$ $=-.211, p<.001)$. LMX was lower for female researchers $(B=-.317, p<.050)$. Perceived societal impact was lower for assistants that combined teaching with research duties $(B=-.111, \mathrm{p}<.050)$ and for researchers in veterinary medicine $(B=-.064, p<.050)$, as compared to $\mathrm{PhD}$ grant recipients and medicine researchers respectively. Job satisfaction was higher for assistants that combined teaching with research duties $(B=.107, \mathrm{p}<.050)$, as well as for postdocs $(B=.136, p<.010)$. Besides its interaction effects, LMX also had direct positive influences on both perceived societal impact $(B=.219, p<.01)$ and job satisfaction $(B=.412, p<.01)$. Other effects are in Appendix 2. To assess the conditional indirect and total effects, we performed a new bootstrapping procedure with 5,000 samples. For the moderated mediation of LMX on job satisfaction through perceived societal impact, the unstandardised conditional indirect effect was .056 (BootCI $=.031-.081, p$ <.010). The index of moderated mediation for perceived societal impact was .019 (BootCI $=.002$ -.050). Taken together, these results lead us to confirm Hypothesis 3(c): we find a moderation mediation, with LMX strengthening the relation between PM consistency and perceived societal impact. However, LMX moderately weakens the direct relation between PM consistency and job satisfaction, leading us to reject Hypothesis 3(b).

[FIGURE 2 NEAR HERE] 
To ease interpretation, we plotted the moderations' separate effects in Figure 3 and Figure 4 (Dawson 2014). In Figure 3, we observe PM consistency to increase perceived societal impact. For academic employees in a high-quality LMX relationship with their research leader, perceived impact is higher, while the slope for LMX stays more-or-less constant. Likewise, in Figure 4, consistent PM increases job satisfaction. However, combined with high PM consistency, the relative contribution of LMX to academic employees' job satisfaction decreases.

\section{[FIGURE 3 NEAR HERE]}

[FIGURE 4 NEAR HERE]

\section{Discussion}

For the benefit of PM effectiveness in public organisations, this study aimed at grasping how PM can avoid unintended effects on employees. We hypothesised that when PM is consistent in the messages it communicates to employees across goal-setting, feedback and evaluation, this would be associated with employees (1) perceiving more societal impact in their work and (2) having higher job satisfaction levels. Furthermore, we argued that these linkages would be stronger in constructive leader-employee relationships.

Based on a study of academic employees, our empirical findings predominantly support our hypotheses, with one notable exception (Hypothesis 3(b)). We demonstrated a moderate positive relation between PM consistency and societal impact (Hypothesis 1(a)), as well as between PM consistency and job satisfaction (Hypothesis 1(b)), suggesting that consistent PM helps employees to perceive impact in and feel satisfied with their job. Subsequently, we observed that part of the effect of PM consistency on job satisfaction was mediated by perceived societal impact (Hypothesis (2)). Finally, we also found support for moderating and moderated mediation effects. 
When LMX is high, the effect of PM consistency on perceived societal impact is stronger (Hypothesis 3(a)), while the mediation effect also increases in size (Hypothesis 3(b)). We also observed LMX moderated the direct relation between PM consistency and job satisfaction, although the direction of this effect was negative and disconfirmed our expectations (Hypothesis 3(c)). In other words, combined with consistent PM, the relative contribution of high-quality LMX relationships to employees' job satisfaction was lower than anticipated.

\section{Theoretical contributions}

From a theoretical point of view, our empirical results suggest that theories of information processing and job design can be combined to arrive at a more comprehensive understanding of PM and its effects on employees. In line with signalling theory (Spence 1973) and its recent application to PM by Biron et al. (2011), our findings suggest that employees might use intraorganisational signals from PM and their leaders to make idiosyncratic interpretations about the societal impact and significance of their job (Alvesson and Kärreman 2007; Ehrnrooth and Björkman 2012). Furthermore, we found that perceived societal impact, as a key psychological state, ultimately influences important outcomes like job satisfaction, supporting job characteristics theory (Morgeson and Humphrey 2006). Combined, these theoretical perspectives endorse a relational approach to PM effectiveness, rooted in intra-organisational communication and work relations. In addition, we make two further contributions to the literature.

As a first contribution, we find that people management matters for employees' wellbeing. This provides empirical support for a nuanced view on PM, in that PM does not necessarily have negative effects on employees' wellbeing but also can entail positive effects, when employees' perceptions of configurational aspects, such as consistency are considered (den Hartog et al. 2013; Jacobsen and Anderson 2014). The more PM is coherent in the messages it communicates to 
employees, the more employees' wellbeing prospers (Van Waeyenberg et al. 2017). When PM is consistent, employees perceive more societal impact in their work and are more satisfied with their job, because PM under this condition has a more optimal 'information advantage' by allowing employees to see how their goals and expectations fit with the public organisation's societal mission and values (Van Dooren, Bouckaert, and Halligan 2015; Selden and Sowa 2011) and a larger 'coordination advantage', reducing stressful conflicting and ambiguous demands by offering clarity and predictability (Fletcher and Williams 1996; Jung 2014).

Consistent PM is more effective in environments where employees have constructive professional relationships with their supervisor, serving as an 'amplifier' of the signals sent by PM (Audenaert et al. forthcoming). Our results confirm this is the case for the relationship between PM consistency and perceived societal impact. However, we cannot reproduce such results for the relation between PM consistency and job satisfaction. Counterintuitively, we observe a negative interaction effect of LMX, suggesting that in constructive supervisor-employee relationships PM consistency's beneficial effects are slightly reduced. This is particularly interesting, as the LMX' potential drawbacks rarely feature in empirical literature. A handful of scholars (Kang and Steward 2007; Kauppila 2015) suggests that having a good relationship with one's supervisor might entail some advantages (e.g., additional information, challenges and opportunities), but could also be subjected to 'diminishing returns'. Being in a leaders' 'in-group', might entail greater demands in the form of larger workloads, stronger obligations and increased personal favours towards the leader in exchange for his or her efforts towards the employee. Such increased demands bear down on employees' wellbeing. Also, they reduce the effect of consistent PM, as they could present increased demands over and above the goals and expectations stipulated by PM. In other words, the joint effects of leader behaviour and PM represent a careful balancing act, further demonstrating 
the need for future research to take leader behaviour into account when studying PM and its outcomes (Butterfield, Edwards, and Woodall 2004; Campbell, Lee, and Im 2016).

Following Moynihan, Pandey, and Wright (2012), our second contribution lies in empirically connecting societal and prosocial values with PM implementation. Such a link was previously suggested (Van Loon, Vandenabeele, and Leisink 2015). However, it was not put to empirical testing. Our findings show that through stimulating employees' perceived societal impact, PM can affect other employee wellbeing aspects, like job satisfaction. Not only does this lend support to the idea that societal impact perceptions are equally important as motivational aspects of public service (Stritch and Christensen 2014; Van Loon et al. 2018), but the unique connection between PM and perceived societal impact also suggests that PM needs to take into account societal and prosocial values to foster employees' positive perceptions (Moynihan and Pandey 2012) and avoid unintended wellbeing effects, such as work alienation (Tummers, Bekkers, and Steijn 2009; 2013). Even in a context as higher education, where PM's relation with societal impact is increasingly questioned (Watermeyer 2015; 2016), consistent PM implementation is positively linked to the societal impact and job satisfaction of academic employees, while constructive leader relationships can play a facilitating role in the process. Overall, this suggests that leadership and PM matter in higher education (Bauwens et al. forthcoming; Broadbent 2010; Decramer et al. 2012), adding to a more nuanced understanding of PM "as a constructive process rather than simply another management activity" (Sella and Sowden 2011, 260).

\section{Practical implications}

Public leaders should be headful of societal impact, since our analyses show it is an important influence for public employees' job satisfaction, while PM is also capable of altering the societal impact employees experience in their job. To avoid that public employees lose connection with the 
social mission and values of the organisation, our empirical observations suggest it is imperative that public leaders streamline PM communication. Goals and expectations should be clearly communicated during goal-setting, while subsequent feedback and evaluation should occur along the lines of those goals and expectations (Van Waeyenberg et al. 2017). When PM is streamlined as such, public employees understand better what is expected of them and how it connects with the societal mission of their public organisation. The decentralisation of PM responsibilities implies that PM should not be considered independent of the leadership of leaders in different echelons of the organisation (Butterfield, Edwards, and Woodall 2004; Campbell, Lee, and Im 2016). Our findings show that PM implementation benefits under constructive leader-employee relationships. Consequentially public organisations should recognize these leaders in this role and offer sufficient training and support employees (Van Thielen et al. 2018; Van Wart 2014), preferably by means of appropriate leader development that combines PM implementation skills with soft skills on constructively dealing with employees.

\section{Limitations and future research outlook}

Notwithstanding we tested moderation effects, we used cross-sectional data, which is prone to CSB (George and Pandey 2017), but also problems of endogeneity. Using cross-sectional data implies that the causal direction between PM, societal impact and job satisfaction cannot be ascertained or that one is able to exclude other factors (e.g., personality traits, societal beliefs) that could be at play. Such problems of reversed causality and omitted variable bias continue to constitute a problem in public administration research, especially in research on societal impact (Stritch and Christensen 2014). To that end, experimental designs are proposed as solution (Bouwman and Grimmelikshuijsen 2016), but also longitudinal data (Stritch 2017), which would help to account for temporal dynamics in how employees perceive PM, LMX and societal impact. 
By examining PM consistency, we heavily relied on employees' perceptions of the PM process (i.e. how PM is conducted as opposed to the goals and desired behaviours that form its content; Bowen and Ostroff 2004). That employees perceive consistency between goals and outcomes of PM does not imply that such perceptions correspond to reality or that employees fully grasp the goals or desired behaviours (Jacobsen and Andersen 2014; Selden and Sowa 2011). In this sense, future research could proceed in two ways. On the one hand, it could take into account other features of the PM process, like the extent to which goals and desired behaviours are visible, legitimate and understood by employees (i.e. PM distinctiveness; Bowen and Ostroff 2004). On the other hand, scholars could jointly examine aspects of the PM process with PM's content (den Hartog et al. 2004), specifically the kind of and extent to which such goals serve a societal purpose. A related limitation is that while leaders can be dutifully consistent in their implementation of PM and maintain high-quality relationships with their followers, this does not imply that they endorse the organisational mission and values (e.g., see studies on strategic commitment and user acceptance; see: George et al. 2018). Subsequent studies could examine how leaders' acceptance of these aspects affects the relation between PM and employee outcomes.

Furthermore, we have studied employees from a single institutional setting (Melo, Sarrico, and Radnor 2010). This poses a potential constraint to the external validity of our findings, as past research asserts that both perceptions of PM (Kalgin et al. 2018) and societal impact (Bellé 2013) are very much context-dependent. While authors like Kalgin et al. (2018) assert that public employees are often aware of the societal contributions of their organisation, it is possible that in certain segments of the public sector the societal contribution of organisational goals might initially be less salient or apparent to employees (e.g., back-office and administrative services), with consequences for the strength and significance of the link between PM and societal impact. Hence, it is up to future research to further unravel the (organisational) contingencies of this relation. Such 
further contextual insights are necessary to advance scholarship on the role of societal impact (Van Loon et al. 2018) and might as well illuminate when and how societal impact impacts other employee attitudes and behaviours, like commitment, engagement and performance in both 'bright' and 'dark' ways (Van Loon, Vandenabeele, and Leisink 2015).

\section{Conclusion}

We contribute to the debate on PM effectiveness in public organisations by examining the conditions under which PM can avoid unintended effects on employees. We focused on two conditions: PM consistency and leadership, as well as how they relate to public employees' perceptions of societal impact and their job satisfaction. Findings show that when PM is consistent in the messages it communicates to employees across goal-setting, feedback and evaluation, employees perceive more societal impact in their work and have higher levels of job satisfaction. These linkages are stronger in constructive leader-employee relationships, although the association between PM consistency and job satisfaction is subjected to 'diminishing returns' in the presence of a constructive leader relationship. Our findings underscore the importance of perceived societal impact as a wellbeing variable in public organisations and public higher education in particular. Furthermore, our findings show that PM and leadership can be complementary, with the ability to boost or buffer each other if required by the situation. Future research may further under unravel the contextual contingencies of the relation between PM (i.e. in terms of process and content), societal impact and other employee outcomes. 


\section{References}

Aguinis, Herman, Jeffrey Edwards, and Kyle Bradley. 2017. "Improving our Understanding of Moderation and Mediation in Strategic Management Research.” Organizational Research Methods 20 (4): 665-685. doi:10.1177/1094428115627498.

Alvesson, Mats and Dan Kärreman. 2007. "Unraveling HRM: Identity, Ceremony, and Control in a Management Consulting Firm" Organization Science 18 (4): 711-723. doi: 10.1287/ orsc. 1070.0267

Anderson, Derrick, Justin Stritch. 2015. “Goal Clarity, Task Significance, and Performance: Evidence From a Laboratory Experiment" Journal of Public Administration Research and Theory 26 (2): 211-225. doi: 10.1093/jopart/muv019

Audenaert, Mieke, Adelien Decramer, Bert George, Bram Verschuere, and Thomas Van Waeyenberg. forthcoming. "When Employee Performance Management Affects Individual Innovation in Public Organizations: The Role of Consistency and LMX.” The International Journal of Human Resource Management. doi:10.1080/09585192.2016.1239220.

Audenaert, Mieke, Alex Vanderstraeten, and Dirk Buyens. 2017. "When Affective Well-Being is Empowered: The Joint Role of Leader-Member Exchange and the Employment Relationship.” The International Journal of Human Resource Management 28 (15): 22082227. doi: 10.1080/09585192.2015.1137610.

Bauer, Tayla and Stephen Green. 1996. "Development of Leader-Member Exchange: A Longitudinal Test.” Academy of Management Journal 39 (6): 1538-1567. doi:10.2307/ 257068. 
Bauwens, Robin, Mieke Audenaert, Jeroen Huisman, and Adelien Decramer. forthcoming. "Performance Management Fairness and Burnout: Implications for Organizational Citizenship Behaviors.” Studies in Higher Education. doi:10.1080/03075079.2017.1389878. Bouwman, Robin, and Grimmelikhuijsen, Stephan 2016. "Experimental Public Administration from 1992 to 2014: A Systematic Literature Review and Ways Forward.” International Journal of Public Sector Management 29 (2): 110-131. doi: 10.1108/IJPSM-07-2015-0129.

Bednall, Timothy, Karin Sanders, and Piety Runhaar. 2014. "Stimulating Informal Learning Activities through Perceptions of Performance Appraisal Quality and Human Resource Management System Strength: A Two-Wave Study.” Academy of Management Learning and Education 13 (1): 45-61. doi: 10.5465/amle.2012.0162.

Bellé, Nicola. 2013. "Leading to Make a Difference: A Field Experiment on the Performance Effects of Transformational Leadership, Perceived Societal Impact, and Public Service Motivation.” Journal of Public Administration Research and Theory 24 (1): 109-136. doi:10.1093/jopart/mut033.

Bernerth, Jeremy, and Herman Aguinis. 2016. "A Critical Review and Best-Practice Recommendations for Control Variable Usage.” Personnel Psychology 69 (1): 229-283. doi:10.1111/peps.12103.

Biron, Michal, Elaine Farndale, and Jaap Paauwe. 2011. "Performance Management Effectiveness: Lessons from World-Leading Firms." The International Journal of Human Resource Management 22 (6): 1294-1311. doi:10.1080/09585192.2011.559100.

Bos-Nehles, Anna, and Mieke Audenaert. 2019. “LMX And HRM: A Multi-Level Review of How LMX is Used to Explain Employment Relationships”. Chap in In: Introduction to Theories of Human Resources and Employment Relations, edited by Keith Townsend, Kenneth Cafferky, Tony Dundon, and Aoife McDermott. Boston, MA: Elgar Publishing. 
Bowen, David, and Cheri Ostroff. 2004. 'Understanding HRM-Firm Performance Linkages: The Role of the 'Strength' of the HRM System." Academy of Management Review 29 (2): 203221. doi: 10.5465/AMR.2004.12736076.

Breaugh, Jessica, Adrian Ritz, and Kerstin Alfes. 2018. "Work motivation and public service motivation: disentangling varieties of motivation and job satisfaction". Public Management Review 20 (10): 1423-1443. doi: 10.1080/14719037.2017.1400580.

Broadbent, Jane. 2010. "If You Can't Measure It, How Can You Manage It? Management and Governance in Higher Educational Institutions” Public Money \& Management 27 (3): 193198, doi: 10.1111/j.1467-9302.2007.00579.x.

Broucker, Bruno, Kurt De Wit, and Liudvika Leisyte. 2016. "Higher Education System Reform: A Systematic Comparison of 10 Countries from an NPM-Perspective." Chap. 2 in Positioning Higher Education: From Here to There, edited by Rosalind Pritchard, Attila Pausits, and James Williams, 19-40. Rotterdam, Netherlands: Sense Publishers. doi: 10.1007/ 978-946300-660-6_2.

Brown, Kerry. 2004. "Human Resource Management in the Public Sector.” Public Management Review 6 (3): 303-309. doi: 10.1080/1471903042000256501.

Butterfield, Reginald, Christine Edwards, and Jean Woodall. 2004. "The New Public Management and the UK Police Service: The Role of the Police Sergeant in the Implementation of Performance Management." Public Management Review 6 (3): 395-415. doi: 10.1080/ 1471903042000256556.

Caillier, James. 2016. "Does Public Service Motivation Mediate the Relationship between Goal Clarity and both Organizational Commitment and Extra-Role Behaviours?" Public Management Review 18 (2): 300-318. doi: 10.1080/14719037.2014.984625. 
Caillier, James. 2017. "The Impact of High-Quality Workplace Relationships in Public Organizations.” Public Administration 95 (3): 638-653. doi:10.1111/padm.12328.

Cammann, Cortlandt, Mark Fichman, Douglas Jenkins, and John Klesh. 1983. "Assessing the Attitudes and Perceptions of Organizational Members." In Assessing Organizational Change: A Guide to Methods, Measures, and Practices, edited by Stanley Seashore, Edward Lawler, Philip Mirvis, and Cortlandt Cammann, 71-138. New York, NY: Wiley.

Campbell, Jesse, Hyunkuk Lee, and Tobin Im. 2016. "At the Expense Of Others: Altruistic Helping Behaviour, Performance Management And Transformational Leadership." Public Management Review 18 (6): 795-818. doi: 10.1080/14719037.2015.1045018.

Cho, Yoon Jik and Theodore Poister. 2013 "Human Resource Management Practices and Trust in Public Organizations." Public Management Review 15 (6): 816-838. doi:10.1080 /14719037.2012.698854.

Crosby, Barbara and John Bryson. 2018. "Why Leadership of Public Leadership Research Matters: and What to do about It". Public Management Review 20 (9): 1265-1286. doi:10.1080/ 14719037.2017.1348731.

Davies, Sarah. 2013. "Research Staff and Public Engagement: A UK Study.” Higher Education 66 (6): 725-739. doi:10.1007/s10734-013-9631-y.

Dawson, Jeremy. 2014. "Moderation in Management Research: What, Why, When, and How." Journal of Business and Psychology 29 (1): 1-19. doi:10.1007/s10869-013-9308-7.

Decramer, Adelien, Mieke Audenaert, Thomas Van Waeyenberg, Tine Claeys, Claudia Claes, Stijn Vandevelde, Jos Van Loon, and Saskia Crucke. 2015. "Does Performance Management Affect Nurses' Well-Being?" Evaluation and Program Planning 49 (1): 98-105. doi:10.1016/j.evalprogplan. 2014.12.018. 
Decramer, Adelien, Carine Smolders, Alex Vanderstraeten, and Johan Christiaens. 2012. "The Impact of Institutional Pressures on Employee Performance Management Systems in Higher Education in the Low Countries." British Journal of Management 23 (S1): S88-S103. doi: 10.1111/j.1467-8551.2012.00820.x.

DeHart-Davis, Leisha, and Sanjay K. Pandey. 2005. "Red Tape and Public Employees: Does Perceived Rule Dysfunction Alienate Managers?" Journal of Public Administration Research and Theory 15 (1): 133-148. doi: 10.1093/jopart/mui007.

den Hartog, Deanne, Paul Boselie, and Jaap Paauwe. 2004. "Performance Management: A Model and Research Agenda." Applied Psychology 53 (4): 556-569. doi: 10.1111/j.1464-0597 .2004.00188.x.

den Hartog, Deanne, Corine Boon, Robert Verburg, and Marcel Croon. 2013. "HRM, Communication, Satisfaction, and Perceived Performance: A Cross-Level Test." Journal of Management 39 (6): 1637-1665. doi: 10.1177/0149206312440118.

Diefenbach, Thomas. 2009. "New Public Management in Public Sector Organizations: The Dark Sides of Managerialistic 'Enlightenment'" Public Administration 87 (4): 892-909. doi: $0.1111 / \mathrm{j} .1467-9299.2009 .01766 . \mathrm{x}$

Dietz, Carolin, and Tabea Scheel. 2017. "Leadership and Presenteeism among Scientific Staff: The Role of Accumulation of Work and Time Pressure." Frontiers in Psychology 8 (1): 18851885. doi: 10.3389/fpsyg.2017.01885.

Edwards, Jeffrey, and Lisa Lambert. 2007. "Methods for Integrating Moderation and Mediation: A General Analytical Framework using Moderated Path Analysis.” Psychological Methods 12 (1): 1-22. doi: 0.1037/1082-989X.12.1.1. 
Ehrnrooth, Mats, and Ingmar Björkman. 2012 "An Integrative HRM Process Theorization: Beyond Signalling Effects and Mutual Gains." Journal of Management Studies 49(6): 1109-1135. doi:10.1111/j.1467-6486.2012.01055.x.

Favero, Nathan, and Justin Bullock. 2014. "How (not) to Solve the Problem: An Evaluation of Scholarly Responses to Common Source Bias." Journal of Public Administration Research and Theory 25 (1): 285-308. doi: 10.1093/jopart/muu020.

Favero, Nathan, Kenneth Meier, and Laurence O’Toole. 2016. “Goals, Trust, Participation, and Feedback: Linking Internal Management with Performance Outcomes.” Journal of Public Administration Research and Theory 26 (2): 327-343. doi:10.1093/jopart/muu044.

Fernandez, Sergio. 2008. "Examining the Effects of Leadership Behavior on Employee Perceptions of Performance and Job Satisfaction”. Public Performance \& Management Review 32 (2): 175-205.doi:10.2753/PMR1530-9576320201.

Fletcher, Clive, and Richard Williams. 1996. "Performance Management, Job Satisfaction and Organizational Commitment." British Journal of Management 7 (2): 169-179. doi:10.1111/j.1467-8551.1996.tb00112.x

Franco-Santos, Monica, and Noeleen Doherty. 2017. "Performance Management and Well-Being: A Close Look at the Changing Nature of the UK Higher Education Workplace." The International Journal of Human Resource Management 28 (16): 2319-2350. doi:10.1080/09585192. 2017.1334148.

Fredman, Nick, and James Doughney. 2012. “Academic Dissatisfaction, Managerial Change and Neo-Liberalism.” Higher Education 64 (1): 41-58. doi:10.1007/s10734-011-9479-y.

George, Bert, Sebastian Desmidt, Eva Cools, and Anita Prinzie. 2018 "Cognitive Styles, User Acceptance and Commitment to Strategic Plans in Public Organizations: An Empirical 
Analysis." Public Management Review 20 (3): 340-359. doi:10.1080/14719037 .2017 .1285112 .

George, Bert, and Sanjay Pandey 2017. "We Know the Yin- But where is the yang? Toward a Balanced Approach on Common Source Bias in Public Administration Scholarship.” Review of Public Personnel Administration 37 (2): 245-270. doi:10.1177/0734371X17698189.

Graen, George, and Mary Uhl-Bien. 1995. "Relationship-Based Approach to Leadership: Development of Leader-Member Exchange (LMX) Theory of Leadership over 25 Years: Applying a Multi-Level Multi-Domain Perspective.” The Leadership Quarterly 6 (2): 219247. doi: 10.1016/1048-9843(95)90036-5.

Grant, Adam. 2012. "Leading with Meaning: Beneficiary Contact, Prosocial Impact, and The Performance Effects of Transformational Leadership.” Academy of Management Journal 55 (2): 458-476. doi: 10.5465/amj.2010.0588..

Grant, Adam. 2007. "Relational Job Design and the Motivation to Make a Prosocial Difference." Academy of Management Review 32 (2): 393-417. doi:10.2307/20159308.

Grant, Adam. 2008. “The Significance of Task Significance: Job Performance Effects, Relational Mechanisms, and Boundary Conditions." Journal of Applied Psychology 93 (1): 108-124. doi: 10.1037/0021-9010.93.1.108.

Hackman, Richard, and Greg Oldham. 1976. "Motivation through the Design of Work: Test of a Theory." Organizational Behavior and Human Performance 16 (2): 250-279. doi:10.1016/0030-5073(76)90016-7.

Harris, Kenneth, Anthony Wheeler, and Michele Kacmar. 2009. "Leader-Member Exchange and Empowerment: Direct and Interactive Effects on Job Satisfaction, Turnover Intentions, and Performance.” Leadership Quarterly 20 (3): 371-82. doi:10.1016/j.leaqua.2009.03.006. 
Hayes, Andrew. 2015. "An Index and Test of Linear Moderated Mediation." Multivariate Behavioral Research 50 (1): 1-22. doi:10.1080/00273171.2014.962683.

Jacobsen, Christian, and Lotte Andersen. 2014. "Performance Management for Academic Researchers: How Publication Command Systems Affect Individual Behavior.” Review of Public Personnel Administration 34 (2): 84-107. doi:10.1177/0734371X13510850.

Jung, Chan. 2014. "Organizational Goal Ambiguity and Job Satisfaction in the Public Sector." Journal of Public Administration Research and Theory 24 (1): 955-981. doi: 10.1093/jopart/mut020.

Kalgin, Alexander, Dmitry Podolskiy, Daria Parfenteva, and Jesse Campbell, J 2018. "Performance management and job-goal alignment: A conditional process model of turnover intention in the public sector". International Journal of Public Sector Management 31 (1): 65-80. doi: 10.1108/IJPSM-04-2016-0069.

Kang, Dae-seok., and Jim Stewart. 2007. "Leader-Member Exchange (LMX) Theory of Leadership and HRD: Development of Units of Theory and Laws of Interaction." Leadership and Organization Development Journal 28 (6): 531-551. doi:10.1108/01437730710780976.

Kauppila, Olli-Pekka. 2015. "When and How Does LMX Differentiation Influence Followers' Work Outcomes? The Interactive Roles of One's Own LMX Status and Organizational Context." Personnel Psychology 69(2): 357-393. doi: 10.1111/peps.12110.

Kerpershoek, Emiel, Martijn Groenleer, and Hans de Bruijn. 2016. "Unintended Responses to Performance Management in Dutch Hospital Care: Bringing Together the Managerial and Professional Perspectives." Public Management Review 18 (3): 417-436. doi:10.1080/ 14719037.2014.985248.

Kline, Rex. 2015. Principles and Practice of Structural Equation Modeling. New York, NY: Guildford press. doi:10.1111/insre.12011_25. 
Knies, Eva, and Peter Leisink. 2018. "People Management in the Public Sector". In HRM in Mission Driven Organizations, edited by Chris Brewster and Jean-Luc Cerdin, 15-46. Cham, Switzerland: Palgrave Macmillan. doi: 10.1007/978-3-319-57583-4_2.

Lee, Geon, Jennifer Benoit-Bryan, and Timothy Johnson. 2012. "Survey Research in Public Administration: Assessing Mainstream Journals with a Total Survey Error Framework.” Public Administration Review 72 (1): 87-97. doi:10.1111/j.1540-6210.2011.02482.x.

Leisink, Peter, and Bram Steijn. 2009. "Public Service Motivation and Job Performance of Public Sector Employees in the Netherlands." International Review of Administrative Sciences 75 (1) 35-52. doi: 10.1177/0020852308099505.

Levecque, Katia, Frederik Anseel, Alain De Beuckelaer, Johan Van der Heyden, and Lydia Gisle. 2017. "Work Organization and Mental Health Problems in PhD Students." Research Policy 46 (4): 868-879. doi:10.1016/j.respol.2017.02.008.

Li, Xiaobei, Karin Sanders, and Stephen Frenkel. 2012. "How Leader-Member Exchange, Work Engagement and HRM Consistency Explain Chinese Luxury Hotel Employees' Job Performance." International Journal of Hospitality Management 31 (4): 1059-1066. doi:10.1016/j.jhm.2012.01.002.

Matta, Fadel, Brent Scott, Jason Colquitt, Joel Koopman, and Liana Passantino. 2017. "Is Consistently Unfair Better than Sporadically Fair? An Investigation of Justice Variability and Stress.” Academy of Management Journal 60 (2): 743-770. doi:10.5465/amj.2014.0455.

McCormack, John, Carol Propper, and Sarah Smith. 2014. "Herding Cats? Management and University Performance.” The Economic Journal 124 (F1): F534-F564. doi:10.1111 lecoj.12105. 
Melo, Ana Isabel, Cláudia Sarrico, and Zoe Radnor. 2010. "The Influence of Performance Management Systems on Key Actors in Universities: The Case of an English University.” Public Management Review 12 (2): 233-254. doi: 10.1080/14719031003616479.

Morgeson, Fredrick., and Stephen Humphrey. 2006. “The Work Design Questionnaire (WDQ): Developing and Validating a Comprehensive Measure for Assessing Job Design and the Nature of Work." Journal of Applied Psychology 91 (6): 399-406. doi: 10.1037/00219010.91.6.1321.

Moynihan, Donald, and Sanjay Pandey. 2007. "The Role of Organizations in Fostering Public Service Motivation." Public Administration Review 67 (1): 40-53. doi: 10.1111/j.15406210.2006.00695.x.

Moynihan, Donald, and Sanjay Pandey. 2010. "The Big Question for Performance Management: Why Do Managers Use Performance Information?”. Journal of Public Administration Research And Theory 20 (4): 849-866. doi: 10.1093/jopart/muq004.

Moynihan, Donald, Sanjay Pandey, and Bradley Wright. 2012. "Prosocial Values and Performance Management Theory: Linking Perceived Social Impact and Performance Information Use.” Governance 25 (3): 463-483. doi:10.1111/j.1468-0491.2012.01583.x.

Noblet, Andrew, and John Rodwell. 2009. "Identifying the Predictors of Employee Health and Satisfaction in an NPM Environment: Testing a Comprehensive and Non-Linear DemandControl-Support Model.” Public Management Review 11 (5): 663-683. doi: $10.1080 / 14719030902798214$.

Oh, Seong and Gregory Lewis. 2009. "Can Performance Appraisal Systems Inspire Intrinsically Motivated Employees?" Review of Public Personnel Administration 29 (2): 158-167. doi: 10.1177/0734371X09331616. 
Oldham, Greg, and Richard Hackman. 2010. "Not What It Was and not What it Will Be: The Future of Job Design Research.” Journal of Organizational Behavior 31 (2-3): 463-479 doi:10.1002/job.678.

Perry, James, and Annie Hondeghem. 2008. Motivation in Public Management: The Call of Public Service. New York, NY: Oxford University Press.

Pick, David, and Stephen Teo. 2017. "Job Satisfaction of Public Sector Middle Managers in the Process of NPM Change.” Public Management Review 19 (5): 705-724. doi: 10.1080/ 14719037.2016.1203012.

Piening, Erk, Alina Baluch, and Hans-Gerd Ridder. 2014. "Mind the Intended-Implemented Gap: Understanding Employees’ Perceptions of HRM.” Human Resource Management 53 (4): 545-567. doi: 10.1002/hrm.21605.

Podsakoff, Philip, Scott MacKenzie, and Nathan Podsakoff. 2012. "Sources of Method Bias in Social Science Research and Recommendations on How to Control it." Annual Review of Psychology 63 (1): 539-569. doi: 10.1146/annurev-psych-120710-100452.

Pollitt, Christopher. 2013. "The Logics of Performance Management.” Evaluation 19 (4): 346363.doi:10.1177/1356389013505040.

Preacher, Kristopher and Andrew Hayes. 2008. “Asymptotic and Resampling Strategies for Assessing and Comparing Indirect Effects in Multiple Mediator Models.” Behavior Research Methods 40 (3): 879-891. doi:10.3758/BRM.40.3.879.

Rosen, Christopher, Kenneth Harris, and Michele Kacmar. 2011. "LMX, Context Perceptions, and Performance: An Uncertainty Management Perspective.” Journal of Management 37 (3): 819-838. doi: 10.1177/0149206310365727.

Rosseel, Yves. 2012. "Lavaan: An R Package for Structural Equation Modeling." Journal of Statistical Software 48 (4): 1-36. doi:10.18637/jss.v048.i02. 
Rowley, Jennifer. 2000 "Is Higher Education Ready for Knowledge Management?." International Journal Of Educational Management 14 (7): 325-333. doi:10.1108/09513540010378978.

Selden, Sally, and Jessica Sowa. 2011. "Performance Management and Appraisal in Human Service Organizations: Management and Staff Perspectives." Public Personnel Management 40 (3): 251-264. doi:10.1177/009102601104000305.

Spence, Michael. 1973. “Job Market Signalling.” Quarterly Journal of Economics 87 (3): 355-374. doi: $10.2307 / 1882010$

Steijn, Bram, and Joris Van der Voet. forthcoming. "Relational Job Characteristics and Job Satisfaction of Public Sector Employees: When Prosocial Motivation and Red Tape Collide.” Public Administration. doi:10.1111/padm.12352.

Stritch, Justin and Robert Christensen. 2014. "Looking at a Job's Societal impact through PSMTinted Lenses: Probing the Motivation-Perception Relationship.” Public Administration 92 (4): 826-842. doi:10.1111/padm.12043.

Stritch, Justin. 2017. "Minding the Time: A Critical Look at Longitudinal Design and Data Analysis in Quantitative Public Management Research.” Review of Public Personnel Administration 37 (2): 219-244. doi: 10.1177/0734371X17697117.

Taylor, Jeannette, and Jonathan Westover. 2011 "Job Satisfaction in the Public Service: The Effects of Public Service Motivation, Workplace Attributes and Work Relations." Public Management Review 13 (5): 731-751. doi: 10.1080/14719037.2010.532959.

Teelken, Christine. 2015. "Hybridity, Coping Mechanisms, and Academic Performance Management: Comparing Three Countries." Public Administration 93 (2): 307-323. doi:10.1111/padm.12138. 
Townsend, Keith, Adrian Wilkinson, Allan Cameron, and Greg Bamber. 2012. "Mixed Signals in HRM: The HRM Role of Hospital Line Managers”. Human Resource Management Journal 22 (3): 267-282. doi: 10.1111/j.1748-8583.2011.00166.x.

Tummers, Lars, Viktor Bekkers, and Bram Steijn. 2009. "Policy Alienation of Public Professionals: Application in a New Public Management Context.” Public Management Review 11 (5): 685-706. doi: 10.1080/14719030902798230.

Tummers, Lars, Victor Bekkers, and Bram Steijn. 2012. "Policy Alienation of Public Professionals: A Comparative Case Study of Insurance Physicians and Secondary School Teachers." International Journal of Public Administration 35 (4): 259-271. doi: 10.1080/ 01900692.2012 .651413

Tummers, Lars and Eva Knies. 2013. "Leadership and Meaningful Work in the Public Sector." Public Administration Review 3 (6): 859-868. doi:10.1111/puar.12138.

Van der Wal, Zeger, Gjalt De Graaf, and Alan Lawton. 2011. “Competing Values in Public Management. Introduction to the Symposium Issue." Public Management Review 13 (3): 331-341. doi:10.1080/14719037.2011.554098.

Van der Weijden, Inge, Maaike Verbree, and Peter Van Den Besselaar. 2012. "From Bench to Bedside: The Societal Orientation of Research Leaders: The Case of Biomedical and Health Research in the Netherlands." Science and Public Policy 39 (3): 285-303. doi:10.1093 /scipol/scr003.

Van Dooren, Wouter, Geert Bouckaert, and John Halligan. 2015. Performance Management in the Public Sector. London, U.K.: Routledge.

Van Loon, Nina, Anne Kjeldsen, Lotte Andersen, Wouter Vandenabeele, and Peter Leisink. 2018. "Only When the Societal Impact Potential is High? A Panel Study of the Relationship 
Between Public Service Motivation and Perceived Performance." Review of Public Personnel Administration 38 (2): 139-166. doi:10.1177/0734371X16639111.

Van Loon, Nina, Wouter Vandenabeele, and Peter Leisink. 2015. "On the Bright and Dark Side of Public Service Motivation: The Relationship Between PSM and Employee Wellbeing." Public Money and Management 35 (5): 349-356. doi:10.1177/0020852308099505.

Van Thielen, Tine, Robin Bauwens, Mieke Audenaert, Thomas Van Waeyenberg, and Adelien Decramer. 2018. "How to Foster the Well-Being of Police Officers: The Role of the Employee Performance Management System.” Evaluation and Program Planning 70 (1): 90-98. doi: 10.1016/j.evalprogplan.2018.07.003.

Van Waeyenberg, Thomas, Adelien Decramer, Sebastian Desmidt, and Mieke Audenaert. 2017. “The Relationship Between Employee Performance Management and Civil Servants' Turnover Intentions: A Test of the Mediating Roles of System Satisfaction and Affective Commitment." Public Management Review 19 (6): 747-764. doi:10.1080/14719037.2016. 1209230.

Van Wart, Montgomery. 2014. Leadership in public organizations: An introduction. New York, NY: Routledge.

Varma, Arup, Pawan Budhwar, and Angelo DeNisi. 2008. Performance Management Systems: A Global Perspective. London, UK: Routledge.

Vigoda-Gadot, Eran, and Itai Beeri. 2011. "Change-Oriented Organizational Citizenship Behavior in Public Administration: The Power of Leadership and the Cost of Organizational Politics." Journal of Public Administration Research and Theory 22 (3): 573-596. doi: 10.1093/jopart/mur036.

Watermeyer, Richard. 2015. "Lost in the 'Third Space': The Impact of Public Engagement in Higher Education on Academic Identity, Research Practice and Career Progression." 
European Journal of Higher Education 5 (3): 331-347. doi:10.1080/21568235 .2015 .1044546 .

Watermeyer, Richard. 2016. "Public Intellectuals Vs. New Public Management: The Defeat of Public Engagement in Higher Education.” Studies in Higher Education 41 (12): 2271-2285. doi: 10.1080/03075079.2015.1034261.

Winter, Richard. 2009. “Academic Manager or Managed Academic? Academic Identity Schisms in Higher Education.” Journal of Higher Education Policy and Management 31 (2): 121131. doi: 10.1080/13600800902825835.

Wright, Bradley and Brian Davis. 2003. "Job Satisfaction in the Public Sector: The Role of the Work Environment." The American Review of Public Administration 33(1): 70-90. doi: $10.1177 / 0275074002250254$.

Wright, Bradley, Donald Moynihan, and Sanjay Pandey. 2012. "Pulling the Levers: Transformational Leadership, Public Service Motivation, and Mission Valence.” Public Administration Review 72 (2): 206-215. doi:10.111/j.1540-6210.2011.02496.x.

Yang, Kaifeng, and Anthony Kassekert. 2009. "Linking Management Reform with Employee Job Satisfaction: Evidence from Federal Agencies." Journal of Public Administration Research and Theory 20 (2):413-436. doi: 10.1093/jopart/mup010.

Yeo, Mabel, Subramaniam Ananthram, Stephen Teo, and Cecil Pearson. 2015. "Leader-Member Exchange and Relational Quality in a Singapore Public Sector Organization.” Public Management Review 17 (10): 1379-1402. doi: 10.1080/14719037.2013.806573. 


\section{Appendix}

Appendix 1. Items and factor loadings (CFA)

Appendix 2. Table with regression results for the final model

\section{Tables}

Table 1. Descriptive statistics, Pearson correlations and Cronbach alphas $(\mathrm{N}=532)$

Table 2. Measurement models from confirmatory factor analysis (CFA)

Table 3. Structural models from structural equation modelling (SEM)

\section{Figures}

Figure 1. Conceptual model.

Figure 2. Path model.

Figure 3. Graphical depiction of the first-stage moderation of LMX.

Figure 4. Graphical depiction of the direct-effect moderation of LMX. 